\title{
Incisional hernia at the site of stoma reversal-incidence and risk factors in a retrospective observational analysis
}

\author{
Andreas Lorenz ${ }^{1} \cdot$ Pamela Kogler $^{1} \cdot$ Reinhold Kafka-Ritsch $^{1} \cdot$ Dietmar Öfner $^{1} \cdot$ Alexander Perathoner $^{1}$ (D)
}

Accepted: 26 April 2019 / Published online: 7 May 2019

(C) The Author(s) 2019

\begin{abstract}
Background The closure of a stoma site has a high incidence of incisional hernia (IH) development, reaching $30 \%$ in some studies. Location and defect size in the abdominal wall depend on the type of stoma formed, most commonly a loop ileostomy or terminal sigmoid colostomy.

Methods The retrospective single-centre study includes all consecutive patients who underwent stoma reversal between 2010 and 2016 at the Department of Visceral, Transplant and Thoracic Surgery in Innsbruck. Patient characteristics and follow-up examinations were evaluated for $\mathrm{IH}$ at both the stoma reversal site and at any other surgical access sites.

Results A total of 181 patients (49\% female, 51\% male) had a stoma reversal operation. A parastomal hernia was present in 5\% $(n=9)$. Follow-up data was available for 140 patients $(77 \%)$. A postoperative IH at the stoma reversal site developed in $15.7 \%$ $(n=22)$ and in $18.6 \%(n=26)$ at other surgical wounds to the abdominal wall during a median follow-up of 136 weeks. The combination of a preoperative parastomal hernia and a postoperative IH was observed in $2.8 \%(n=5)$. Parastomal herniation, male sex, body mass index over 25 , arterial hypertension and concomitant ventral hernia were associated with IH formation at the stoma reversal.

Conclusion The rate of $\mathrm{IH}$ at the stoma reversal site was lower than expected from the literature, whereas the rate of IH at other surgical wounds to the abdominal wall was within the expected range.
\end{abstract}

Keywords Stoma reversal $\cdot$ Incisional hernia $\cdot$ Ileostomy $\cdot$ Rectal cancer

\section{Introduction}

\section{Background}

Formation of an intestinal stoma is an important tool in the surgeon's repertoire to control or prevent abdominal sepsis and treat bowel obstruction. In an elective setting, the most common application is a temporary diverting ileostomy in order to 'protect' a critical bowel anastomosis after resection of the rectum and prevent leakage of faeces into the abdominal cavity. In other cases, inflammatory or neoplastic diseases might make an anastomosis unfeasible and a stoma is a quick and safe means for securing intestinal function (e.g.

Alexander Perathoner

alexander.perathoner@i-med.ac.at

1 Department of Visceral, Transplant and Thoracic Surgery, Center of Operative Medicine, Medical University of Innsbruck, Anichstraße 35, 6020 Innsbruck, Austria
Hartmann's procedure in patients with perforated sigmoid diverticulitis; transverse colostomy in patients with bowel obstruction due to metastatic cancer).

Regardless of the underlying disease, a stoma significantly impacts on patients' activities of daily life, social and sexual function. This, apart from directly stoma-related morbidity, incentivizes patients and surgeons to carry out a reversal operation restoring the intestinal passage and closing the defect in the abdominal wall. The latter usually involves a direct suture repair of the fascia and various techniques to address the inevitable wound contamination by the abounding commensals of the intestinal tract. Wound infection after abdominal wall closure is found to be a risk factor for incisional hernia (IH) formation in some studies [1] whereas others do not confirm this [2]. Regardless of its direct effect, it influences the discussion of suture materials and preventive measures such as mesh reinforcement. These are called for because the incidence of $\mathrm{IH}$ is as high as $34 \%$, and the affected patients frequently are subjected to a subsequent hernia repair operation [3]. Other reported risk factors for $\mathrm{IH}$ formation at 
the stoma site include obesity, diabetes mellitus, chronic obstructive lung disease and arterial hypertension [4]. Many other factors (smoking, suture technique, sex, priority of operation, hypoalbuminemia, anaemia, cardiovascular disease, renal failure, systemic glucocorticoid medication, ASA score, underlying disease, prior and following laparotomies, history of hernia, concomitant hernia, type of stoma, interval of stoma in situ, type of skin closure, length of hospital stay) have been examined but not found to influence IH incidence to a level of statistical significance [2].

\section{Objectives}

The aim of this retrospective cohort study is to determine the rate of IH in our patients and to test the hypothesis that modifiable and non-modifiable risk factors for IH formation are present.

\section{Material and methods}

This manuscript was written in accordance with the STROBE statement: Strengthening the reporting of observational studies in epidemiology [5].

\section{Study design and setting}

A retrospective cohort was analysed for its incidence of incisional hernias at the stoma site after stoma reversal operation at the department of Visceral, Transplant and Thoracic surgery of the Medical University of Innsbruck, Austria. The ileostomy reversal operation often is performed as teaching operation by surgical trainees under direct supervision of a colorectal surgeon. Colostomy reversals were performed by consultant surgeons or advanced trainees. Closure of the abdominal wall defect at the stoma site was performed with interrupted stitches of an absorbable braided suture (Vicryl or Polysorb USP 1) after clearing of fascia margins as per the institutional standard. The method of skin closure was not uniform: direct skin closure with a Penrose drain was replaced by the purse-string closure method during the last year of the study period.

As a centre for tertiary referral and surgical oncology, a comprehensive oncological follow-up clinic is established and all patients with a tubular gastrointestinal malignancy are examined clinically and by CT scan every 6 months in the first 2 years, followed by 12 monthly examinations until 5 years postoperatively. Some oncological patients were not subjected to standardised follow-up because of a decision to provide best supportive care, limited disease or advanced age. Non-oncologic patients were not subject to systematic followup, and clinical or radiologic examination was only performed on request of the surgeon or when mandated by unrelated medical conditions.

CT scans were examined by radiology consultants and surgeons independently. Incisional hernia was diagnosed clinically and radiologically. The development of an $\mathrm{IH}$ at the stoma reversal site was noted as well as IH at other abdominal wall incisions (laparotomy or laparoscopy). For parastomal hernias, the intraoperative (re)affirmation of the diagnosis by the surgeon at the time of stoma reversal was required. All demographic, surgical, clinical and radiological data were entered into an Excel file (Microsoft Corp., USA) and analysed with SPSS (IBM SPSS Statistics 24, IBM Corp., USA).

\section{Participants}

The eligibility criteria for the study cohort were all consecutive patients who underwent a stoma reversal operation at our department between 2010 and 2016. The patients were identified by querying the electronic operating room log using the procedure codes for ileostomy and colostomy reversal.

\section{Variables}

From the electronic medical records, patient baseline data was acquired for the perioperative hospitalisation period: age, sex, disease type (either colon cancer, rectal cancer, gynaecological cancer, inflammatory bowel disease, diverticulitis, bowel perforation -not diverticulitis, cystic fibrosis and other), TNM stage, UICC stage, body mass index, length of stay, chemotherapy, radiotherapy, time since last bowel movement before the stoma reversal, time to first bowel movement after the reversal operation, smoking and drinking habits, maximum postoperative C-reactive protein, creatinine, estimated glomerular filtration rate (MDRD-IDMS), blood glucose, temperature, blood pressure and heart rate as well as minimum haemoglobin during the perioperative hospitalisation period, and the following comorbidities: diabetes mellitus, cardiovascular disease (history of myocardial infarction, congestive heart failure $\mathrm{CHF}$, coronary heart disease, peripheral vascular disease), arterial hypertension, chronic kidney disease, chronic obstructive pulmonary disease (COPD), systemic steroid treatment and history of abdominal wall hernia.

From the follow-up examinations, data on $\mathrm{IH}$ at the site of stoma reversal or at any other surgical access site, symptomatic IH, IH repair operation, time from operation to $\mathrm{IH}$, time followed up and death during followup were extracted.

Primary outcome was the occurrence of an $\mathrm{IH}$ at the site of stoma reversal. Secondary outcome was the occurrence of $\mathrm{IH}$ at any other surgical access site. An IH was defined as published in the European Hernia Society statement on abdominal wall hernias [6]. 


\section{Statistical methods}

Primary and secondary endpoints were assessed using survival time and time-to-event analysis (Kaplan-Meier). Continuous variables were assessed using mean and standard deviation and median and quartiles. Categorical data was processed using absolute and relative incidence, and Fisher's exact test was used to evaluate for significant contingency $(p<0.05$ indicating significance). For the multivariate analysis, a binary logistic regression was performed. Calculations were done using the SPSS Software (IBM SPSS Statistics 24, IBM Corp., USA).

\section{Results}

\section{Participants}

From the operating room logbook, 198 patients with a stoma reversal operation from 2010 to 2016 were identified. Seventeen patients were excluded because a stoma reversal was not performed, a mesh reinforcement was used or the stoma was reestablished at the same site. The study cohort includes 181 patients, of whom 41 were lost to follow-up. A flowchart is shown in Fig. 1.

\section{Descriptive data}

The baseline data are given in Table 1 for the 181 patients that underwent a stoma reversal and for a subset of 71 patients that were followed up in our oncology clinic for rectal cancer after ileostomy reversal. For the entire group $(n=181)$, the patients had a mean age of 53.5 years, $48.6 \%$ were female and the underlying disease was a malignancy in $59.1 \%$ of cases. The majority of operations concerned ileostomies $(92.2 \%)$, and only $7.8 \%$ of patients had a colostomy. Terminal stomas were a minority (14.9\%) in contrast to $85.1 \%$ loop ostomies. Almost $60 \%$ of patients presented with a body mass index (BMI) in the normal range (18.5-25.0) and comorbidities were infrequent, arterial hypertension in $23 \%$ of cases being the diagnosis most often observed. A parastomal hernia was noted during the stoma reversal operation in $5.6 \%$ of cases, a history of abdominal wall hernia was given in $6.8 \%$ of cases. The mean length of stay was 21.5 days (median 10.5, P25-75: $8.0-15.75)$ and almost a third of patients dropped their estimated glomerular filtration rate (eGFR) below $60 \mathrm{ml} / \mathrm{min} /$ $1.74 \mathrm{~m}^{2}$ during the perioperative hospitalisation. The subgroup including only the rectal cancer patients $(n=71)$ differed in sex (67.6\% males), obesity rates (37.3\% overweight), length of stay (mean 13.5 days, median 10 days, P25-75: 8.015.0 ) and reduced eGFR in over $60 \%$ of cases. In $26.6 \%$ of
Fig. 1 Flowchart of retrospective patient recruitment to study the incidence of incisional hernia after stoma reversal

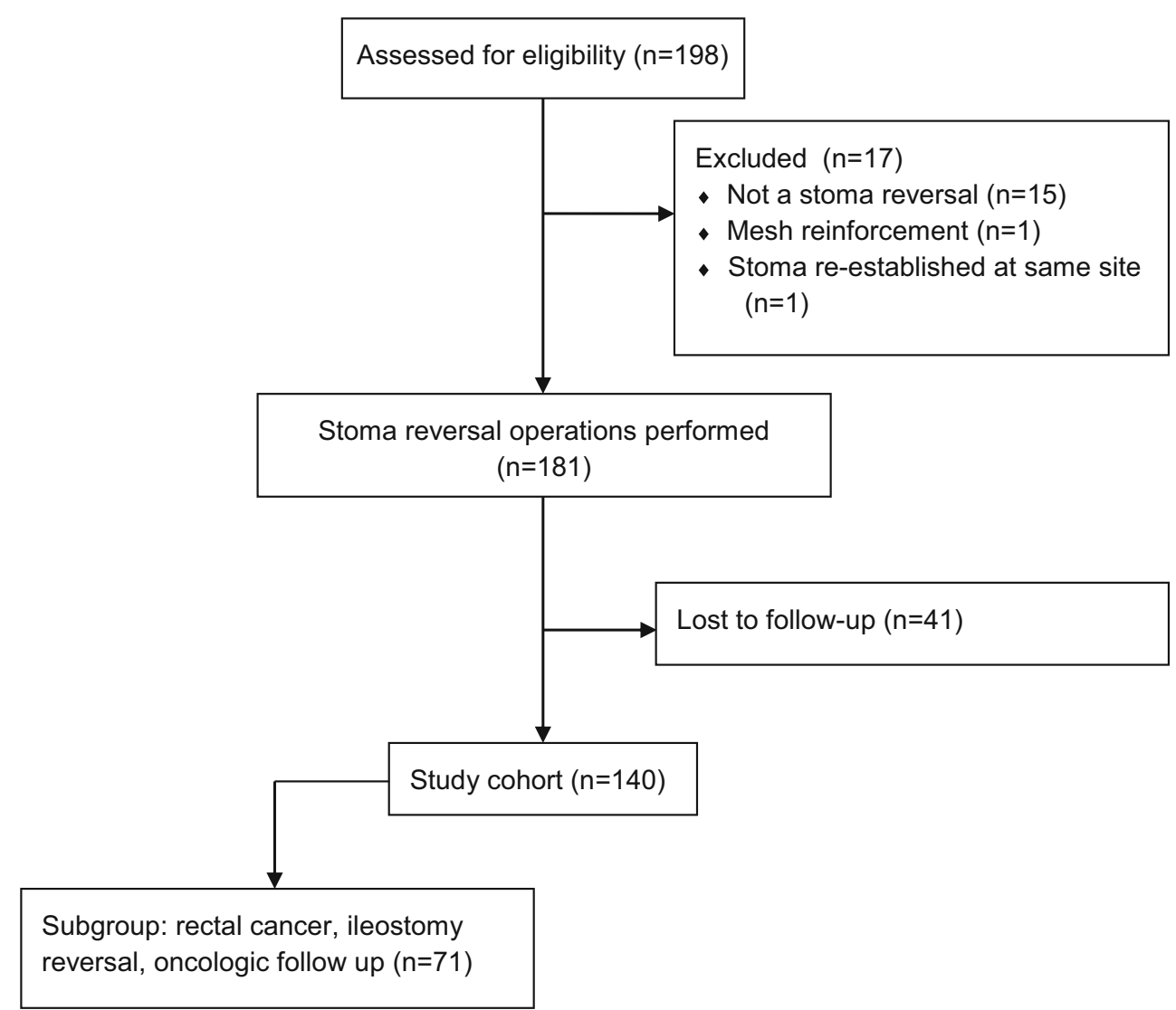


Table 1 Descriptive statistics at baseline for all patients with a stoma reversal operation $(N=181)$

Patient data

$\%(n / N)^{\mathrm{a}}$ or Mean $(\mathrm{SD})^{\mathbf{b}}$ All patients $(N=181)$

\begin{tabular}{|c|c|c|}
\hline Age & 53.5 & $(23.3)$ \\
\hline Sex (female) & 48.6 & $(88 / 181)$ \\
\hline \multicolumn{3}{|l|}{ Diagnosis } \\
\hline Rectal cancer & 44.2 & $(80 / 181)$ \\
\hline Colon cancer & 7.2 & $(13 / 181)$ \\
\hline Gynaecologic cancer & 7.7 & $(14 / 181)$ \\
\hline Diverticulitis & 8.3 & $(15 / 181)$ \\
\hline Inflammatory bowel disease & 3.3 & $(6 / 181)$ \\
\hline Perforation & 5.0 & $(9 / 181)$ \\
\hline Cystic fibrosis & 3.9 & $(7 / 181)$ \\
\hline Other & 20.4 & $(37 / 181)$ \\
\hline BMI (available in $N=179$ ) & 22.1 & $(5.33)$ \\
\hline$<18.5$, underweight & 23.5 & $(42 / 179)$ \\
\hline 18.5-25.0, normal weight & 50.3 & $(90 / 179)$ \\
\hline 25.0-30.0, overweight & 19.6 & $(35 / 179)$ \\
\hline 30.0-35.0, class I obesity & 4.5 & $(8 / 179)$ \\
\hline $35.0-40.0$, class II obesity & 2.2 & $(4 / 179)$ \\
\hline$>40.0$, class III obesity & 0 & $(0 / 179)$ \\
\hline Non-smokers & 76.1 & $(89 / 117)$ \\
\hline Non-drinkers & 65.3 & $(77 / 118)$ \\
\hline \multicolumn{3}{|l|}{ Comorbidities } \\
\hline Diabetes mellitus & 10.7 & $(19 / 178)$ \\
\hline Cardiovascular disease (except arterial hypertension) & 9.0 & $(16 / 178)$ \\
\hline Arterial hypertension & 23.0 & $(31 / 178)$ \\
\hline Chronic kidney disease & 3.4 & $(6 / 178)$ \\
\hline COPD & 5.6 & $(10 / 178)$ \\
\hline Systemic steroid treatment & 2.8 & $(5 / 178)$ \\
\hline Neoadjuvant oncological treatment & 57.5 & $(46 / 80)$ \\
\hline History of abdominal wall hernia & 6.8 & $(8 / 118)$ \\
\hline \multicolumn{3}{|l|}{ Laboratory parameters during hospitalisation } \\
\hline CRP maximum (mg/dl) & 12.1 & $(9.97)$ \\
\hline Haemoglobin minimum (g/l) & 103 & $(20.20)$ \\
\hline Creatinine maximum (mg/dl) & 1.21 & $(1.15)$ \\
\hline Estimated glomerular filtration rate (MDRD-IDMS ${ }^{\mathrm{c}}$ ) & 72.8 & $(51.48)$ \\
\hline Kidney injury in hospital (defined as eGFR $<60 \mathrm{ml} / \mathrm{min} / 1.73 \mathrm{~m}^{2}$ ) & 31.8 & $(57 / 179)$ \\
\hline Length of stay (days) & 21.5 & $(42.72)$ \\
\hline Parastomal hernia & 5.0 & $(9 / 181)$ \\
\hline Teaching operation (performed by surgical trainee) & 26.6 & $(47 / 177)$ \\
\hline \multicolumn{3}{|l|}{ Type of stoma } \\
\hline Ileostoma & 92.2 & $(166 / 181)$ \\
\hline Colostoma & 7.8 & $(15 / 181)$ \\
\hline Terminal ostomy & 14.9 & $(27 / 181)$ \\
\hline Loop ostomy & 85.1 & $(154 / 181)$ \\
\hline
\end{tabular}

$B M I$ body mass index, $C O P D$ chronic obstructive pulmonary disease, $C R P$ C-reactive protein, $e G F R$ estimated glomerular filtration rate ${ }^{\text {a }} \%(n / N) n=$ number of patients $/ N=$ total number of patients

${ }^{\mathrm{b}}$ Mean (SD) mean value of variable (standard deviation)

${ }^{c}$ Modification of Diet in Renal Disease Study equation based on isotope dilution mass spectrometry traceable creatinine measurement 
cases, the operation was performed by a surgical trainee, the rest by board certified surgeons.

\section{Outcome data}

The outcome data analysis includes 140 patients, 41 patients were excluded because they were lost to follow-up. An incisional hernia at the stoma reversal site was observed in 22 patients $(15.7 \%)$ during a mean follow-up of 32.2 months (2.7 years) resulting in an incidence rate of 5.8 per 100 person-years. For the subgroup of rectal cancer patients with complete oncologic follow-up, the $\mathrm{IH}$ rate was $16.9 \%$ during a mean follow-up of 36.8 months (3.1 years) resulting in an incidence rate of 5.5 per 100 person-years. Incisional hernias at other surgical access sites were diagnosed in 18.6 and $29.6 \%$ for the two patient groups (all patients vs. rectal cancer patients), respectively; a hernia repair operation was performed in 26.2 and $23.1 \%$ of those patients, respectively (Table 2). Classification of the observed incisional hernias according to the European Hernia Society [7] is provided in Table 3.

The incidence of $\mathrm{IH}$ at the stoma site over time for the subgroup of 71 rectal cancer patients is given in Fig. 2. The mean time to the event of $\mathrm{IH}$ at the stoma site was 9.7 months, the median 3.4 months of follow-up.

\section{Risk factors}

Possible risk factors were analysed for their impact on the development of IH after stoma reversal operations. Fisher's exact test was used to compare significant differences between groups and a multivariate analysis (binary logistic regression) was performed for selected risk factors (Table 4). Male sex, increased BMI, arterial hypertension and presence of a parastomal hernia at time of the stoma reversal were statistically significant in this analysis.

\section{Discussion}

\section{Key results}

Incisional hernias at the site of stoma reversal were observed in $15.7 \%$ with a mean follow-up time of 32.2 months (or 2.7 years). In the studied cohort, male sex, high BMI, arterial hypertension and presence of a parastomal hernia at the time of the reversal operation were risk factors for developing an $\mathrm{IH}$ at the stoma site.

\section{Limitations}

In this retrospective analysis, baseline data was not adequately recorded in all cases. Additionally, follow-up was performed systematically only for a subgroup of patients. The majority of procedures were ileostomy reversals, and findings might deviate for more challenging colostomy reversals. A selection bias towards patients fit enough to have a non-mandatory stoma reversal operation exists. Not all parameters of interest could be ascertained retrospectively from the operation notes to a level of completeness that allowed statistical analysis, e.g. suture size and type, suture technique (full thickness bites vs. fascia-only, running vs. interrupted), proximity of the stoma site to the midline and most importantly, the rate of surgical site infection (SSI). As SSIs were not systematically monitored for and the number of recorded incidents was exceptionally low, we chose not to include them in our analysis. The low case number is responsible for imprecision in the calculated numbers, as seen by sizeable confidence intervals and stretches between percentiles.

\section{Interpretation}

The overall rate of incisional hernias at the stoma site after reversal operation at our institution was $15.7 \%$. This lies at the
Table 2 Incisional hernia (IH) incidence and repair

\begin{tabular}{lll}
\hline & $\begin{array}{l}\text { All patients with } \\
\text { follow-up }(N=140)\end{array}$ & $\begin{array}{l}\text { Subgroup: patients with ileostomy } \\
\text { reversal and oncologic follow-up } \\
\text { for rectal cancer }(N=71)\end{array}$ \\
\hline $\begin{array}{l}\text { Follow-up (weeks since stoma reversal) } \\
\text { Mean (SD) }\end{array}$ & $140.1(92.22)$ & $160.0(96.59)$ \\
$\quad$ Median (P25-P75) & $137.9(61-214)$ & $142.6(70-227)$ \\
$\begin{array}{l}\text { IH at stoma reversal site } \\
\text { Incidence of stoma IH (\%) }\end{array}$ & $15.7(22 / 140)$ & $16.9(12 / 71)$ \\
$\quad$ Median time to stoma IH (P25-75) & $31.4(8.8-57.1)$ & $28.6(7.2-61.2)$ \\
$\begin{array}{l}\text { IH at any other surgical access site } \\
\text { Incidence of other IH (\%) }\end{array}$ & $18.6(26 / 140)$ & $29.6(21 / 71)$ \\
Hernia repair & & $23.1(6 / 26)$ \\
Incidence of hernia operations $(\%)$ & $26.8(11 / 41)$ & \\
\hline
\end{tabular}

$S D$ standard deviation, $P 25$ 25th percentile, $P 7575$ th percentile 
Table 3 European Hernia Society classification of the observed incisional hernia $(N=41)$

$\%(n / N)^{\mathrm{a}}$ or median $(\mathrm{P} 25-\mathrm{P} 75)$

\begin{tabular}{ll}
\hline Midline incisional hernia $^{\mathrm{b}}$ & \\
M1 subxiphoidal & $0(0 / 41)$ \\
M2 epigastric & $43.9(18 / 41)$ \\
M3 umbilical & $75.6(31 / 41)$ \\
M4 infraumbilical & $14.6(6 / 41)$ \\
M5 suprapubic & $0(0 / 41)$ \\
Lateral incisional hernia & 0 \\
Recurrent incisional hernia & 0 \\
Measurements & \\
Length $(\mathrm{cm})$ & $4(1.9-8)$ \\
Width $(\mathrm{cm})$ & $3.65(1.7-5)$ \\
Width classification & \\
W1 $<4 \mathrm{~cm}$ & $53.6(22 / 41)$ \\
W2 $\geq 4-10 \mathrm{~cm}$ & $43.9(18 / 41)$ \\
W3 $\geq 10 \mathrm{~cm}$ & $2.4(1 / 41)$ \\
\hline
\end{tabular}

$P 25$ 25th percentile, $P 75$ 75th percentile

${ }^{\text {a }} \%(n / N) n=$ number of patients $/ N=$ total number of patients

${ }^{\mathrm{b}}$ For hernias extending over more than one $\mathrm{M}$ zone, each affected zone was counted

lower end of the spectrum reported in the literature (up to $31 \%$ ) [3, 4, 8-10]. Striving for a more precise analysis, a subgroup of patients with ileostomy reversal after low anterior resection for rectal cancer with systematic oncological followup including regular CT scans was studied. These patients had a just slightly higher incidence of IH at the stoma site (16.9 vs. $15.7 \%)$.

Fig. 2 Percentage of patients with an incisional hernia $(\mathrm{IH})$ at the stoma reversal site over time (survival curve) of 71 patients following ileostomy reversal during oncologic follow-up for rectal cancer
The rate of incisional hernia at any other surgical access site to the abdomen was high with $18.6 \%$ overall and $29.6 \%$ in the rectal cancer subgroup. In the literature, even higher rates (up to $45 \%$ [8]) are reported during comparable follow-up times. The difference between the overall rate and the rate of the rectal cancer subgroup might be attributed to the systematic follow up including multiple CT scans per patient, with high sensitivity in detection of asymptomatic, small abdominal wall hernias [11]. The low rate of significant comorbidities, especially obesity, might be responsible for the favourable outcome of our patients when compared to the literature. Nevertheless, the known measures to reduce IH rates (see EHS guidelines on laparotomy closure [12]) need to be enforced. From a technical point of view, closure of the fascia was made by interrupted short-term absorbable sutures and thus contrary to current recommendation by the EHS guidelines for primary abdominal closure, albeit the closure of the stoma defect is a secondary one, for which there is no generally accepted recommendation.

Some risk factors for IH formation were identified that have not previously been reported, i.e. male sex and arterial hypertension. The latter possibly was a surrogate marker for metabolic syndrome in our cohort, and the former might be explained by a higher mean BMI (male 24 , female 20 ) and a sex-specific higher prevalence of intraabdominal fat with subsequent higher stress on the abdominal wall. An increased BMI is a known risk factor for IH formation and was confirmed in our patients [13]. Finally, the presence of a parastomal hernia has not been explicitly named as a risk factor for IH formation before our study, but the recurrence rates for any type of hernia repair (especially without mesh reinforcement) are known to be high in any setting (46\% and

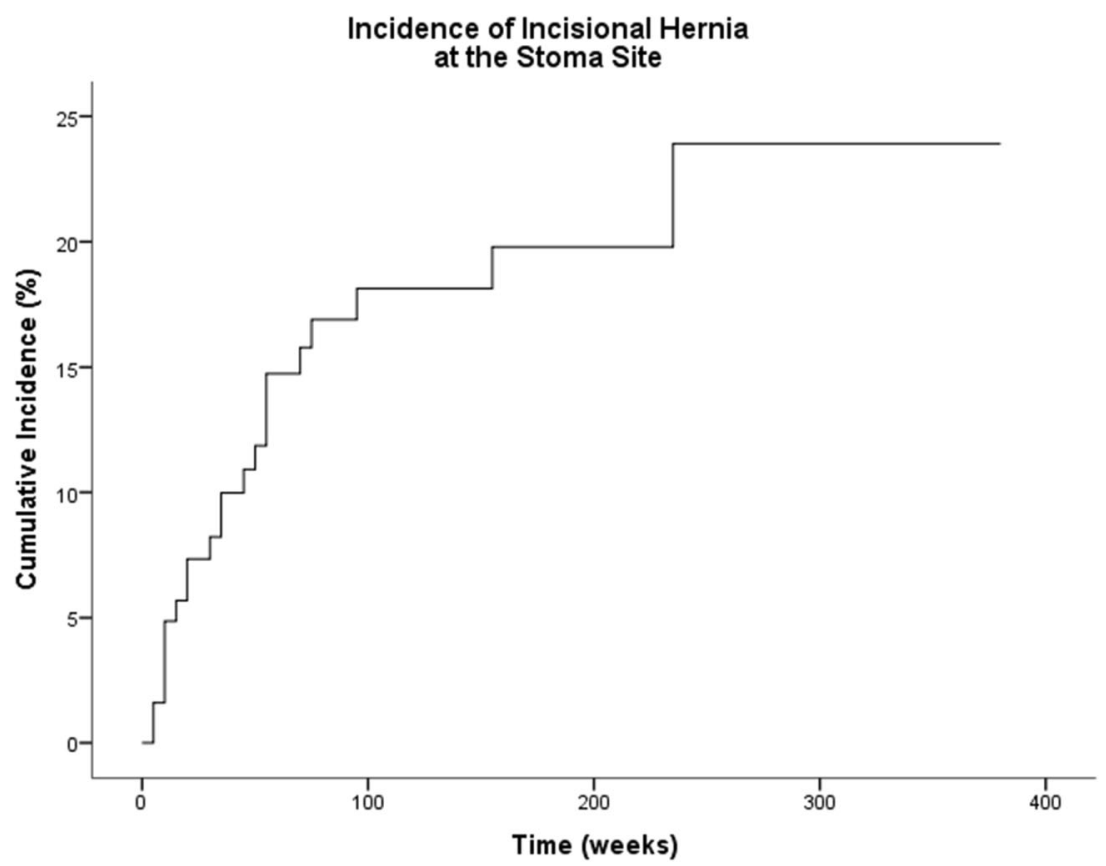


Table 4 Analysis of risk factors for incisional hernia (IH) at the stoma reversal site $(N=140)$

\begin{tabular}{|c|c|c|c|c|}
\hline \multicolumn{2}{|l|}{ Variable } & \multicolumn{2}{|l|}{ Univariate analysis } & \multirow{2}{*}{$\begin{array}{l}\text { Multivariate analysis } \\
\text { Binary logistic } \\
\text { regression } p \text { value }\end{array}$} \\
\hline & Prevalence $(\%)$ & $\begin{array}{l}\text { Odds ratio ( } 95 \% \\
\text { confidence interval) }\end{array}$ & $\begin{array}{l}\text { Fisher's exact } \\
\text { test } p \text { value }\end{array}$ & \\
\hline Age $\geq 65$ vs. $<65$ years & $45.7 \%$ & $1.72(0.79-3.75)$ & 0.128 & 0.496 \\
\hline Sex (female vs. male) & $45.0 \%$ & $0.27(0.09-0.76)$ & 0.005 & 0.030 \\
\hline Body mass index $\geq 25$ vs. $<25$ & $26.3 \%$ & $4.93(2.20-10.99)$ & $<0.001$ & 0.003 \\
\hline Length of Stay (days) $\geq 12$ vs. $<12$ & $40.7 \%$ & $1.21(0.56-2.62)$ & 0.395 & - \\
\hline UICC stage $\geq$ III vs. $<$ III & $40.0 \%$ & $1.50(0.63-3.59)$ & 0.263 & - \\
\hline Smoking & $26.1 \%$ & $0.22(0.03-1.58)$ & 0.070 & - \\
\hline Drinking & $36 \%$ & $1.30(0.49-3.43)$ & 0.402 & - \\
\hline \multicolumn{5}{|l|}{ Laboratory parameters during hospitalisation } \\
\hline $\mathrm{CRP}$ maximum $\geq 15$ vs. $<15(\mathrm{mg} / \mathrm{dl})$ & $31.4 \%$ & $1.02(0.45-2.32)$ & 0.574 & - \\
\hline Haemoglobin minimum $<90$ vs. $\geq 90$ (g/l) & $26.4 \%$ & $0.44(0.14-1.40)$ & 0.108 & 0.607 \\
\hline $\begin{array}{l}\text { Estimated glomerular filtration rate }\left(\text { MDRD-IDMS }{ }^{\mathrm{a}}\right) \\
\text { minimum }<60 \mathrm{vs} . \geq 60\left(\mathrm{ml} / \mathrm{min} / 1.73 \mathrm{~m}^{2}\right)\end{array}$ & $39.8 \%$ & $0.93(0.42-2.08)$ & 0.531 & - \\
\hline \multicolumn{5}{|l|}{ Comorbidities } \\
\hline Diabetes mellitus & $9.4 \%$ & $1.52(0.52-4.44)$ & 0.343 & - \\
\hline Cardiovascular disease (except arterial hypertension) & $8.7 \%$ & $1.77(0.48-6.49)$ & 0.603 & - \\
\hline Arterial hypertension & $23.9 \%$ & $2.65(1.26-5.59)$ & 0.013 & 0.030 \\
\hline $\begin{array}{l}\text { Hypertensive blood pressure (maximum systolic) } \\
\text { during hospital stay ( } \geq 160 \mathrm{vs} .<160 \mathrm{mmHg} \text { ) }\end{array}$ & $25.5 \%$ & $2.55(1.04-6.29)$ & 0.047 & - \\
\hline Systemic steroid treatment & $3.6 \%$ & $1.27(0.21-7.63)$ & 0.586 & - \\
\hline Neoadjuvant treatment & $31.2 \%$ & $1.53(0.71-3.30)$ & 0.203 & - \\
\hline Parastomal hernia & $5.0 \%$ & $5.59(2.93-10.64)$ & 0.001 & 0.002 \\
\hline IH at other surgical access sites & $18.6 \%$ & $3.04(1.46-6.33)$ & 0.007 & 0.418 \\
\hline History of abdominal wall hernia & $7.5 \%$ & $3.36(1.21-9.26)$ & 0.067 & 0.431 \\
\hline Teaching operation (performed by surgical trainee) & $26.6 \%$ & $1.23(0.48-3.14)$ & 0.442 & - \\
\hline
\end{tabular}

UICC Union for International Cancer Control

${ }^{a}$ Modification of Diet in Renal Disease Study equation based on isotope dilution mass spectrometry traceable creatinine measurement

${ }^{\mathrm{b}}$ Only variables with a significance level of $80 \%$ or higher in Fisher's exact analysis were included. Smoking was excluded due to missing data (tobacco use unknown for 47 of 140 patients)

23\% 3-year cumulative rate for suture repair and mesh repair respectively, according to [1]).

A number of trials exist that evaluate prophylactic mesh reinforcement of the abdominal wall either at the time of stoma reversal or at the time of stoma creation (e.g. keyhole technique). The ROCCS trial (University of Birmingham, ClinicalTrials.gov: NCT02238964) and the ILEOCLOSE trial (University of Vall d'Hebron, Barcelona, clinicaltrials. gov: NCT02226887) are ongoing to examine the use of biological and absorbable synthetic meshes. A number of prospective trials have already shown the safety, efficacy and benefit of using prophylactic meshes. A recent, larger, matched-case series used a non-absorbable synthetic mesh on the posterior rectus sheath with very promising results (IH rate of $1 \%$ vs. $17 \%$, [14]). Based on our institutional data, a randomised controlled trial to further test prophylactic mesh implantation should only be undertaken on a multicentre level lest it be underpowered.

\section{Implications for patient care}

Gastrointestinal stoma formation offers few technical variations: fixation with sutures and possibly a rod; the stoma opening must be wide enough for the intestine, but should not cause incisional hernias; if the stoma opening is too small, it leads to impaired blood perfusion and faecal obstruction. When considering implantation of non-absorbable meshes, bacterial contamination associated with a high risk of wound infection has to be taken into account. In addition, every mesh augmentation of a stoma has the same basic flaw, i.e. the opening through which the intestine has to pass (e.g. keyhole technique, sandwich technique). Prophylactic mesh reinforcement therefore is quite controversial, especially in temporary stomas and it is a moot point, whether expensive mesh reinforcement during transient stoma creation is indicated when the ostomy reversal is planned a few months later. After stoma reversal surgery, wound healing disorders occur in up to $41 \%$ 
of cases [15], hardly avoidable because of the high bacterial load. Non-absorbable mesh implantation therefore is to be carefully considered. When a non-biological material is implanted, different techniques are to be considered: regarding SSIs, the best place would be outside the peritoneal cavity and without contact with the subcuticular plane; regarding hernia prevention, the ideal place from a biomechanical point of view is the rectus sheath, but the anatomical structures are often disturbed by previous procedures and thus an anatomical correct preparation is difficult. In a recent multicentre randomised controlled trial, an epifascial (i.e. onlay) mesh had the best effect in IH prophylaxis [16]. In our study cohort, $75.6 \%$ (31/41) of patient were not operated for their IH either because they were oligosymptomatic or unwilling to undergo additional surgery. Therefore, the burden of disease might be lowered considerably by prophylactic mesh reinforcement at the time of stoma reversal.

Stomas are maintenance-intensive and often limit the patient's activities either physically or psychologically and many patients actively demand a stoma reversal. Due to a perioperative morbidity of over $50 \%$ and significant comorbidities [17], many patients after sigmoid perforation never have their stomas reversed. Nineteen percent of patients after low anterior resection for rectal cancer received a permanent stoma in a recent trial [18]. Thus, it is crucial for these patients to create an optimal stoma to guarantee uncomplicated ostomy care and prevent development of a parastomal hernia. The rate of parastomal hernias in our study was low, as only stoma reversals were analysed which are typically performed within the first 6 months after stoma formation. Stoma hernias carry a high burden of disease, with incarceration being a rare but serious complication. Surgical repair is performed in up to $56 \%$ of cases [19] but is plagued with a high recurrence rate (about $75 \%$ in direct repair and up to $16 \%$ in mesh repair, [20]).

In our collective, nine patients had a parastomal hernia; of those, five patients developed an IH at the stoma reversal site. This might be attributed to significantly damaged or thinned out tissue in these cases.

Based on the findings in our study and literature, we see no need for temporary stoma formation with mesh reinforcement, as the parastomal hernia rate is low and mesh use is a significant cost factor. At the time of stoma reversal, prophylactic mesh reinforcement can be considered depending on the known risk factors (i.e. parastomal, concurrent $\mathrm{IH}$, obesity, possibly also sex and arterial hypertension) but there is little evidence to support it. In case of an IH after stoma reversal, mesh reinforcement is indicated as in any incisional hernia repair. Furthermore, patients should be encouraged and provided with multimodal support in reducing modifiable risk factors (i.e. obesity) prior to an elective procedure.

\section{Conclusion}

Incisional hernias at the stoma reversal site as well as at other surgical access sites occurred with relevant incidence in this study. Obesity and presence of a parastomal hernia were identified as significant risk factors.

Acknowledgements Open access funding provided by University of Innsbruck and Medical University of Innsbruck.

Author contributions All authors meet all of the following three conditions:

1. Authors make substantial contributions to conception and design, and/or acquisition of data, and/or analysis and interpretation of data.

2. Authors participate in drafting the article or revising it critically for important intellectual content.

3. Authors give final approval of the version to be submitted and any revised version to be published.

\section{Compliance with ethical standards}

Conflict of interest The authors declare that they have no conflict of interest.

Disclosures Andreas Lorenz, Pamela Kogler, Alexander Perathoner, Reinhold Kafka-Ritsch and Dietmar Öfner have nothing to disclose.

Study approval This study was approved by the ethics committee of the Medical University of Innsbruck (reference ECS 1064/2018).

Open Access This article is distributed under the terms of the Creative Commons Attribution 4.0 International License (http:// creativecommons.org/licenses/by/4.0/), which permits unrestricted use, distribution, and reproduction in any medium, provided you give appropriate credit to the original author(s) and the source, provide a link to the Creative Commons license, and indicate if changes were made.

\section{References}

1. Luijendijk RW, Hop WC, van den Tol MP et al (2000) A comparison of suture repair with mesh repair for incisional hernia. N Engl J Med 343:392-398

2. Bosanquet DC, Ansell J, Abdelrahman T, Cornish J, Harries R, Stimpson A, Davies L, Glasbey JCD, Frewer KA, Frewer NC, Russell D, Russell I, Torkington J (2015) Systematic review and meta-regression of factors affecting midline incisional hernia rates: analysis of 14,618 patients. PLoS One 10:e0138745

3. Bhangu A, Fletcher L, Kingdon S, Smith E, Nepogodiev D, Janjua U (2012) A clinical and radiological assessment of incisional hernias following closure of temporary stomas. Surgeon 10:321-325

4. Guzman-Valdivia G (2008) Incisional hernia at the site of a stoma. Hernia 12:471-474

5. von Elm E, Altman DG, Egger M, Pocock SJ, Gøtzsche PC, Vandenbroucke JP (2007) The Strengthening the Reporting of Observational Studies in Epidemiology (STROBE) statement: guidelines for reporting observational studies. Lancet 370:14531457

6. Muysoms F, Campanelli G, Champault GG, DeBeaux AC, Dietz UA, Jeekel J, Klinge U, Köckerling F, Mandala V, Montgomery A, 
Morales Conde S, Puppe F, Simmermacher RKJ, Śmietański M, Miserez M (2012) EuraHS: the development of an international online platform for registration and outcome measurement of ventral abdominal wall hernia repair. Hernia 16:239-250

7. Muysoms FE et al (2009) Classification of primary and incisional abdominal wall hernias. Hernia 13(4):407-414

8. De Keersmaecker G, Beckers R, Heindryckx E et al (2016) Retrospective observational study on the incidence of incisional hernias after reversal of a temporary diverting ileostomy following rectal carcinoma resection with follow-up CT scans. Hernia 20: 271-277

9. Schreinemacher MF, Vijgen GJ, Dagnelie PC, Bloemen JG, Huizinga BF, Bouvy ND (2011) Incisional hernias in temporary stoma wounds: a cohort study. Arch Surg 146:94-99

10. Nguyen MT, Phatak UR, Li LT, Hicks SC, Moffett JM, Arita NA, Berger RL, Kao LS, Liang MK (2014) Review of stoma site and midline incisional hernias after stoma reversal. J Surg Res 190:504 509

11. Baucom RB, Beck WC, Holzman MD, Sharp KW, Nealon WH, Poulose BK (2014) Prospective evaluation of surgeon physical examination for detection of incisional hernias. J Am Coll Surg 218: 363-366

12. Muysoms FE, Antoniou SA, Bury K, Campanelli G, Conze J, Cuccurullo D, de Beaux AC, Deerenberg EB, East B, Fortelny RH, Gillion JF, Henriksen NA, Israelsson L, Jairam A, Jänes A, Jeekel J, López-Cano M, Miserez M, Morales-Conde S, Sanders DL, Simons MP, Śmietański M, Venclauskas L, Berrevoet F, European Hernia Society (2015) European Hernia Society guidelines on the closure of abdominal wall incisions. Hernia 19:1-24

13. Walming S, Angenete E, Block M, Bock D, Gessler B, Haglind E (2017) Retrospective review of risk factors for surgical wound dehiscence and incisional hernia. BMC Surg 17:19

14. Warren JA, Beffa LR, Carbonell AM et al (2018) Prophylactic placement of permanent synthetic mesh at the time of ostomy closure prevents formation of incisional hernias. Surgery 2018 Apr 163(4):839-846

15. Hackam DJ, Rotstein OD (1995) Stoma closure and wound infection: an evaluation of risk factors. Can J Surg 38:144-148

16. Jairam AP, Timmermans L, Eker HH, Pierik REGJM, van Klaveren D, Steyerberg EW, Timman R, van der Ham AC, Dawson I, Charbon JA, Schuhmacher C, Mihaljevic A, Izbicki JR, Fikatas P, Knebel P, Fortelny RH, Kleinrensink GJ, Lange JF, Jeekel HJ, Nieuwenhuizen J, Hop WCJ, Burger PCW, Verhagen HJ, Klitsie PJ, van de Berg M, Golling M (2017) Prevention of incisional hernia with prophylactic onlay and sublay mesh reinforcement versus primary suture only in midline laparotomies (PRIMA): 2-year follow-up of a multicentre, double-blind, randomised controlled trial. Lancet 390:567-576

17. Bell C, Asolati M, Hamilton E, Fleming J, Nwariaku F, Sarosi G, Anthony T (2005) A comparison of complications associated with colostomy reversal versus ileostomy reversal. Am J Surg 190:717720

18. Lindgren R, Hallbook O, Rutegard J et al (2011) What is the risk for a permanent stoma after low anterior resection of the rectum for cancer? A six-year follow-up of a multicenter trial. Dis Colon Rectum 54:41-47

19. Ripoche J, Basurko C, Fabbro-Perray P, Prudhomme M (2011) Parastomal hernia. A study of the French federation of ostomy patients. J Visc Surg 148:e435-e441

20. Krishnamurty DM, Blatnik J, Mutch M (2017) Stoma complications. Clin Colon Rectal Surg 30:193-200

Publisher's note Springer Nature remains neutral with regard to jurisdictional claims in published maps and institutional affiliations. 